\title{
Research
}

\section{Risk prediction models for symptomatic patients with bladder and kidney cancer:}

\author{
a systematic review
}

\begin{abstract}
Background

Timely diagnosis of bladder and kidney cancer is key to improving clinical outcomes. Given the challenges of early diagnosis, models incorporating clinical symptoms and signs may be helpful to primary care clinicians when triaging at-risk patients.
\end{abstract}

\section{Aim}

To identify and compare published models that use clinical signs and symptoms to predict the risk of undiagnosed prevalent bladder or kidney cancer

\section{Design and setting}

Systematic review.

\section{Method}

A search identified primary research reporting or validating models predicting the risk of bladder or kidney cancer in MEDLINE and EMBASE. After screening identified studies for inclusion, data were extracted onto a standardised form. The risk models were classified using TRIPOD guidelines and evaluated using the PROBAST assessment tool.

\section{Results}

The search identified 20661 articles. Twenty studies (29 models) were identified through screening. All the models included haematuria (visible, non-visible, or unspecified), and seven included additional signs and symptoms (such as abdominal pain). The models combined clinical features with other factors (including demographic factors and urinary biomarkers) to predict the risk of undiagnosed prevalent cancer. Several models ( $n=13)$ with good discrimination (area under the receiver operating curve $>0.8$ ) were identified; however, only eight had been externally validated. All of the studies had either high or unclear risk of bias.

\section{Conclusion}

Models were identified that could be used in primary care to guide referrals, with potential to identify lower-risk patients with visible haematuria and to stratify individuals who present with non-visible haematuria. However, before application in general practice, external validations in appropriate populations are required.

\section{Keywords}

bladder cancer; early diagnosis; kidney cancer; risk prediction; systematic review.

\section{INTRODUCTION}

Bladder and kidney cancer are the ninth and 15th most common cancers worldwide, respectively. In the UK, bladder and kidney cancers each account for approximately $3 \%$ of new cancer cases, and 5300 and 4500 annual deaths, with their incidence expected to rise. ${ }^{1,2}$ Early-stage diagnosis is strongly correlated with improved survival rates for both bladder and kidney cancer., ${ }^{1,2}$

The majority of bladder and kidney cancers $(75 \%$ and $59 \%$, respectively) are diagnosed following a referral from primary care in the UK. ${ }^{1-3}$ A prolonged primary care interval (from patient presentation to referral) is associated with worse clinical outcomes. ${ }^{4,5}$ Currently, in England, median diagnosis time for bladder and kidney cancer - after presentation in primary care with a relevant clinical feature - is 51 and 70 days, respectively, with variation seen by symptom.

Visible haematuria $(\mathrm{VH})$ is present in the majority of patients with bladder cancer (53\%), however, it is less common in individuals diagnosed with kidney cancer (18\%). ${ }^{7}$ Currently, the National Institute for Health and Care Excellence guidelines advise urgent referral for suspected bladder or kidney cancer for unexplained

H Harrison, MSci, MPhil, DPhil, research associate; JA Usher-Smith, MA, MPhil, PhD, MRCGP, university lecturer; S Griffin, MSc, DM MDhc, FRCGP, FMedSci, DLSHTM, professor of general practice; Y Zhou, MSc, MRCGP, clinical research fellow, The Primary Care Unit, Department of Public Health and Primary Care, University of Cambridge, Cambridge. L Li, medical student; L Roberts, medical student; Z Lin, medical student; RE Thompson, medical student, University of Cambridge School of Clinical Medicine, Addenbrooke's Hospital, Cambridge. SH Rossi, BSc, MRCS, academic clinical fellow; GD Stewart; BSc, PhD Edin, MA Cantab,

FRCSEd (Urol), professor of surgical oncology, Department of Surgery, University of Cambridge, Addenbrooke's Hospital, Cambridge. FM Walter MA, MD, FRCGP, joint director, The Primary Care non-visible haematuria (NVH) or persistent $\mathrm{VH}$ in all individuals aged 60 and 45 years, respectively. ${ }^{8}$ Although $5.1 \%$ of people with $\mathrm{VH}$ in a primary care setting are ultimately diagnosed with urological cancers, the positive predictive value (PPV) of $\mathrm{NVH}$ is less certain and may be as low as $1.6 \%$ in primary care. ${ }^{7}$ The focus on haematuria may impede early identification of cancers that present atypically or with a number of non-specific symptoms. ${ }^{6,9}$ This could also lead to the over-referral of lower-risk individuals presenting with haematuria. ${ }^{10}$

Risk assessment tools have the potential to improve timely diagnosis of cancer by combining multiple clinical features to identify symptomatic patients who would benefit from early referral and reducing investigations in individuals least likely to benefit. 7.11 Risk models to guide clinical decision making are becoming more common. For example, the QCancer tool, which estimates the risk of 11 cancers based on symptoms and patient characteristics, has been integrated into primary care software. ${ }^{12}$ Although not routinely used to aid referral decisions for suspected cancer, risk assessment tools have been identified as a potential method for improving UK cancer outcomes. ${ }^{13}$

Unit, Department of Public Health and Primary Care, University of Cambridge, Cambridge, and director. Wolfson Institute of Population Health, Queen Mary University of London, London. Address for correspondence

Hannah Harrison, The Primary Care Unit, Department of Public Health and Primary Care, University of Cambridge, Cambridge CB2 1TN, UK.

Email: hh504dmedschl.cam.ac.uk

Submitted: 19 May 2021; Editor's response: 19 July 2021; final acceptance: 25 August 2021. CThe Authors

This is the full-length article (published online 30 Nov 2021) of an abridged version published in print. Cite this version as: Br J Gen Pract 2021. DOI: https://doi.org/10.3399/BJGP.2021.0319 


\section{How this fits in}

Timely diagnosis of bladder and kidney cancer from primary care is key to improving survival rates, but remains challenging. Risk models have been suggested as a possible tool to guide clinicians in making referral decisions, particularly in individuals who present atypically. This systematic review identified a number of models that may be of interest, in particular, models able to identify low-risk individuals who may not require referral and a model suitable for stratifying risk in individuals with non-visible haematuria. However, only a small number of models included clinical features other than haematuria and there was a lack of external validations.

In this review, published models that incorporate symptoms and signs (referred to as clinical features) and estimate the risk of undiagnosed prevalent bladder or kidney cancer at an individual level were systematically identified and compared. The review focuses on the risk factors included in the models, the performance of the models (discrimination and calibration), and their potential use in primary care.

\section{METHOD}

A systematic review was performed following an a priori established study protocol (PROSPERO ID: CRD42018116967).

An electronic literature search of MEDLINE and EMBASE was performed in November 2018 and updated in December 2020. Literature published 1980-2020 was included, using a combination of subject headings incorporating 'bladder or renal/ kidney or urinary-tract cancer', 'risk or risk factor or chance' and 'model or prediction or score' (see Supplementary Table S1 and S2).

Studies were included that fulfil all of the following criteria:

- are published, peer-reviewed, primary research;

- present a model, which here is considered the use of a combination of $\geq 2$ factors to identify individuals with a higher risk of undiagnosed prevalent bladder or kidney cancer. Studies predicting recurrent or future risk were excluded;

- incorporate at least one clinical feature as a risk factor;

- include at least one quantitative measure of model performance /discrimination, calibration, or accuracy). Accepted measures include (but are not limited to) area under the receiver operating curve (AUROC), $R^{2}$ (goodness of fit), sensitivity, specificity, PPVs, and negative predictive values (NPVs). Graphical measures alone were not accepted; and

- are applicable to the general population. Studies including only specific groups for example, individuals receiving dialysis - were excluded.

One reviewer carried out the search. Reviewers screened titles and abstracts to exclude clearly irrelevant articles. Pilot screening was carried out to ensure consistency between reviewers. The full text was examined, by two reviewers, if a definite decision to exclude could not be made based on the title and abstract alone. Disagreements were resolved by discussion with a third reviewer.

Data extraction was carried out independently by two reviewers for all included studies. Where studies included multiple different models all were included separately. Details of model development, validation, and performance were extracted into a standardised form. Included studies were classified according to the TRIPOD guidelines. ${ }^{14}$ The PROBAST tool was used to assess risk of bias (RoB) over four domains of interest (population, risk factors, outcomes, and analysis).15,16 Information required for this assessment was extracted by two reviewers, and one reviewer scored the studies. A second reviewer checked the RoB assessment process.

\section{RESULTS}

After duplicates were removed, the search identified 20661 articles. Of these, 19959 were excluded by title and abstract screening, and 686 after full-text assessment. Twenty studies were identified, describing 29 models that satisfied the inclusion criteria (Figure 1). 10,17-35

\section{Study design and setting}

Of the 20 studies, 16 were cohort studies $^{10,17,19-30,33,34}$ and four were casecontrol studies ${ }^{18,31,32,35}$ (see Supplementary Table S3). Six studies were performed in a UK primary care setting, using routinely coded data. ${ }^{22-24,31,32,35}$ Nine were conducted in secondary (or specialist) care settings, including hospital outpatient clinics and urology departments. ${ }^{10,18,21,26-28,30,33,34}$ The remaining five studies do not provide enough information about the study setting to be classified as primary or secondary 17,19,20,25,29 


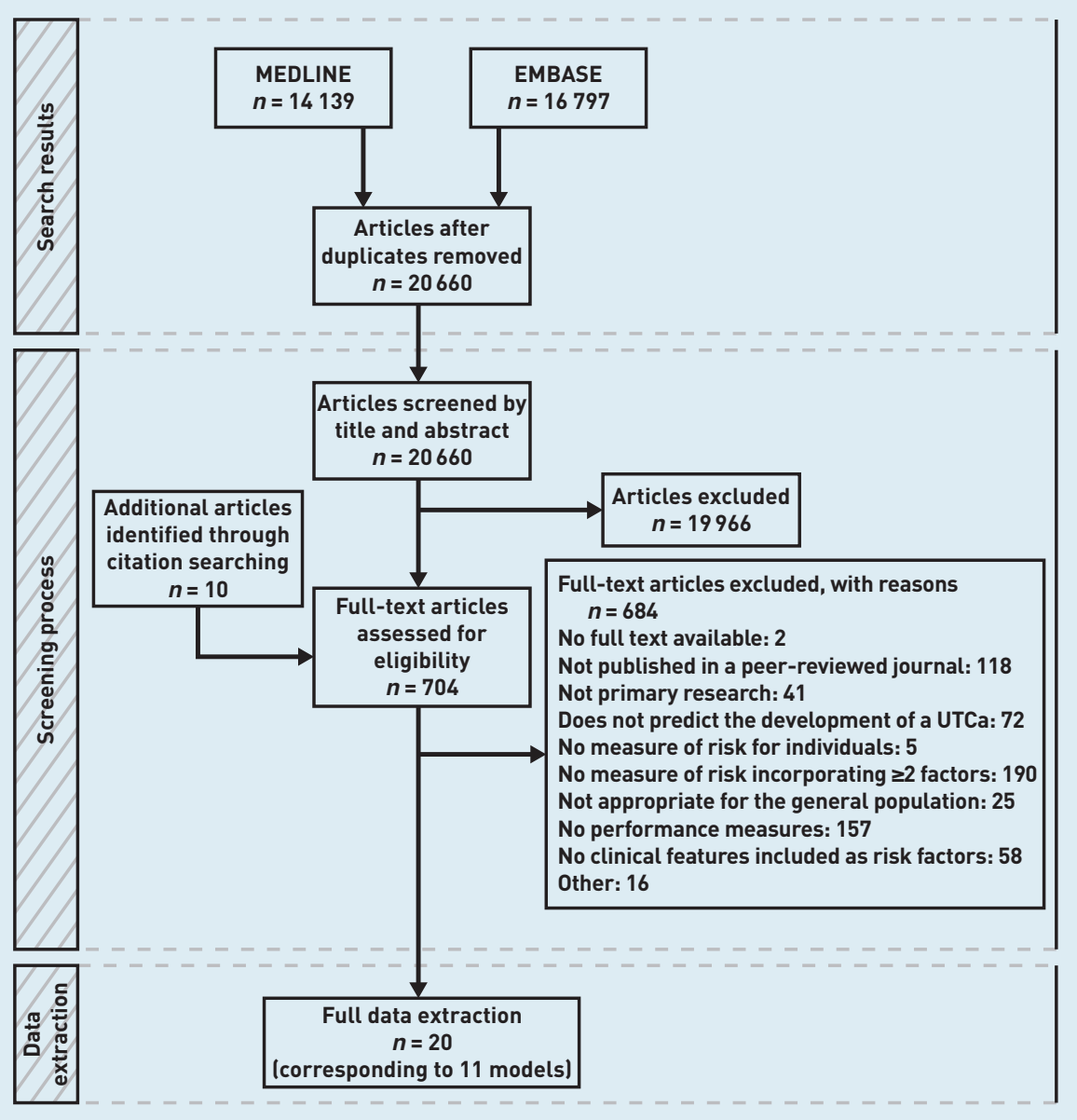

Figure 1. PRISMA flow diagram. UTCa = urinary tract cancer. (for example, referring to recruitment at a 'clinic').

Most studies included European $(n=11)$ or North American populations ( $n=8)$; two studies were based in South East Asia. ${ }^{21,26}$ The six studies in a primary care setting included a mixture of asymptomatic and symptomatic individuals. 22-24,31,32,35 Eleven studies included patients undergoing investigationforhaematuria, 10,18-21,26,27,28,30,33,34 in some cases restricted to $\mathrm{NVH}(n=2)^{27,34}$ or painless haematuria $(n=4)^{18-20,26}$ Three studies included individuals classified as high-risk based on a prior history of haematuria ${ }^{30}$ or smoking status. ${ }^{17,29}$ One study included all individuals enrolled on a health insurance plan who underwent urinalysis..$^{25}$

Of the 29 models (Table 1), the outcomes were a diagnosis of bladder cancer ( $n=19),{ }^{17-21,29,32-35}$ kidney cancer $(n=1),{ }^{31}$ or urological cancer ( $n=9$ ) (bladder and kidney cancer, either with ${ }^{10,22,25}$ or without $23,24,27,28$ cancers of the urothelium). Most models were developed in mixed-sex populations, although a small number were developed specifically for males $(n=2)^{22,23}$ and females ( $n=2) .22,24$ The majority of the models were developed using logistic regression $(n=22)$, although other methodologies, including survival models $(n=2)$, were also found. Internalvalidation - either bootstrapping ${ }^{17-20}$ or split-sampling (random ${ }^{22-24,34}$ or nonrandom ${ }^{28,29}$ ) - has been carried out for 22 models. Only eight models have been externally validated. ${ }^{10,25,27,28}$

\section{Risk factors}

Haematuria was included as a risk factor in all of the included models (see Supplementary Table S4). However, there was significant variation in the type of haematuria included. Four models used only $\mathrm{VH}_{1}{ }^{22,31,32}$ four only $\mathrm{NVH}^{25,28,34}$ and 14 included both las separate risk factors $[n=2]^{25,35}$ or the degree of haematuria was used as a risk factor $[n=12]^{18-21,29,33}$. In seven models, the type of haematuria was unspecified. 17,23,24

Most studies $(n=14)$ reported the association between haematuria and the outcome of interest lsee

\section{Table 1. Summary of included models}

\begin{tabular}{|c|c|c|c|c|c|c|c|c|c|c|c|}
\hline \multirow{3}{*}{$\begin{array}{l}\text { Modela lauthor } \\
\text { [year], }{ }^{\text {ref }} \text { model] }\end{array}$} & \multirow[b]{3}{*}{ Outcome } & \multicolumn{8}{|c|}{ Summary of risk factors } & \multirow[b]{3}{*}{ Validation ${ }^{\mathrm{b}}$} & \multirow{3}{*}{$\begin{array}{l}\text { Developmen } \\
\text { setting }\end{array}$} \\
\hline & & \multicolumn{4}{|c|}{ Demographic and lifestyle } & \multicolumn{3}{|c|}{ Clinical symptoms and signs } & \multirow{2}{*}{$\begin{array}{l}\text { Test } \\
\text { results }\end{array}$} & & \\
\hline & & Age & Sex & Smoking & Other & Haematuria & System specific & Non-specific & & & \\
\hline $\begin{array}{l}\text { Hippisley-Cox } \\
(2012)_{,}{ }^{22} \text { a }\end{array}$ & $\begin{array}{l}\mathrm{KCa}, \mathrm{BCa}, \\
\mathrm{UCa}\end{array}$ & - & - & $x$ & $x$ & $\mathrm{VH}$ & $\begin{array}{l}\text { Abdominal } \\
\text { pain }\end{array}$ & $\begin{array}{l}\text { Appetite loss, } \\
\text { weight loss, } \\
\text { anaemia }\end{array}$ & - & Internally & $P$ \\
\hline $\begin{array}{l}\text { Hippisley-Cox } \\
(2012),{ }^{22} \text { b }\end{array}$ & $\begin{array}{l}\mathrm{KCa}, \mathrm{BCa}, \\
\mathrm{UCa}\end{array}$ & - & - & $x$ & $x$ & VH & $\begin{array}{l}\text { Abdominal } \\
\text { pain }\end{array}$ & $\begin{array}{l}\text { Appetite loss, } \\
\text { weight loss, } \\
\text { anaemia }\end{array}$ & - & Internally & $P$ \\
\hline $\begin{array}{l}\text { Hippisley- } \\
\text { Cox 2013), }{ }^{23} \text { a }\end{array}$ & KCa, BCa & $x$ & - & $x$ & $x$ & Unspecified & $\begin{array}{l}\text { Abdominal } \\
\text { pain }\end{array}$ & $\begin{array}{l}\text { Night sweats, } \\
\text { weight loss }\end{array}$ & - & Internally & $P$ \\
\hline
\end{tabular}


Table 1 continued. Summary of included models

\begin{tabular}{|c|c|c|c|c|c|c|c|c|c|c|c|}
\hline \multirow{3}{*}{$\begin{array}{l}\text { Model }^{\text {a }} \text { lauthor } \\
\text { [year], }{ }^{\text {ref }} \text { model] }\end{array}$} & \multirow[b]{3}{*}{ Outcome } & \multicolumn{8}{|c|}{ Summary of risk factors } & \multirow[b]{3}{*}{ Validation $^{\mathrm{b}}$} & \multirow{3}{*}{$\begin{array}{c}\text { Development } \\
\text { setting }\end{array}$} \\
\hline & & \multicolumn{4}{|c|}{ Demographic and lifestyle } & \multicolumn{3}{|c|}{ Clinical symptoms and signs } & \multirow{2}{*}{$\begin{array}{l}\text { Test } \\
\text { results }\end{array}$} & & \\
\hline & & Age & Sex & Smoking & Other & Haematuria & System specific & Non-specific & & & \\
\hline $\begin{array}{l}\text { Hippisley- } \\
\text { Cox (2013), }{ }^{24} \text { b }\end{array}$ & KCa, BCa & $x$ & - & $x$ & $x$ & Unspecified & $\begin{array}{l}\text { Abdominal pain, } \\
\text { postmenopausal } \\
\text { bleeding }\end{array}$ & $\begin{array}{l}\text { Anaemia, appetite } \\
\text { loss, indigestion, } \\
\text { weight loss }\end{array}$ & - & Internally & $P$ \\
\hline $\begin{array}{l}\text { Shephard } \\
(2012)^{32}\end{array}$ & $\mathrm{BCa}$ & $x$ & - & - & - & VH & $\begin{array}{l}\text { Dysuria, } \\
\text { abdominal pain, } \\
\text { UTI }\end{array}$ & - & $x$ & None & $P$ \\
\hline Price $(2014)^{35}$ & $\mathrm{BCa}$ & $x$ & - & - & - & $\begin{array}{l}\text { VH and } \\
\mathrm{NVH}\end{array}$ & $\begin{array}{l}\text { Dysuria, } \\
\text { abdominal pain, } \\
\text { UTI }\end{array}$ & Constipation & $x$ & None & $P$ \\
\hline Jung (2011), ${ }^{25} \mathrm{a}$ & $\begin{array}{l}\mathrm{KCa}, \mathrm{BCa} \\
\mathrm{UCa}\end{array}$ & $x$ & - & - & - & $\begin{array}{l}\text { VH or } \\
\mathrm{NVH}\end{array}$ & - & - & - & Externally & $U$ \\
\hline Jung $(2011),{ }^{25} \mathrm{~b}$ & $\begin{array}{l}\mathrm{KCa}, \mathrm{BCa} \\
\mathrm{UCa}\end{array}$ & $x$ & - & - & - & $\mathrm{NVH}$ & - & - & - & Externally & U \\
\hline Loo (2013), ${ }^{28}$ a & $\mathrm{KCa}, \mathrm{Bca}$ & $x$ & $x$ & $x$ & - & $\begin{array}{l}\text { NVH and } \\
\text { history }\end{array}$ & - & - & - & Externally & $\mathrm{S}$ \\
\hline Loo (2013), ${ }^{28}$ b & $\mathrm{KCa}, \mathrm{Bca}$ & $x$ & $x$ & $x$ & - & $\begin{array}{l}\text { NVH and } \\
\text { history }\end{array}$ & - & - & - & Externally & S \\
\hline Beukers (2013), ${ }^{18}$ a & $\mathrm{BCa}$ & $x$ & $x$ & - & - & Degree & - & - & $x$ & Internally & S \\
\hline Beukers (2013), ${ }^{18}$ b & $\mathrm{BCa}$ & $x$ & $x$ & - & - & Degree & - & - & $x$ & Internally & S \\
\hline Cha (2012), ${ }^{19}$ a & $\mathrm{BCa}$ & $x$ & $x$ & $x$ & - & Degree & - & - & - & Internally & U \\
\hline Cha (2012), ${ }^{19}$ b & $\mathrm{BCa}$ & $x$ & $x$ & $x$ & - & Degree & - & - & $x$ & Internally & $U$ \\
\hline Cha (2012), ${ }^{19} \mathrm{C}$ & $\mathrm{BCa}$ & $x$ & $x$ & $x$ & - & Degree & - & - & $x$ & Internally & $U$ \\
\hline Hee $(2013)^{21}$ & $\mathrm{BCa}$ & $x$ & $x$ & $x$ & - & Degree & - & - & - & Externally & S \\
\hline Lotan (2009), , ${ }^{29}$ a & $\mathrm{BCa}$ & $x$ & $x$ & $x$ & $x$ & Degree & - & - & - & Internally & U \\
\hline Lotan (2009), ${ }^{29}$ b & $\mathrm{BCa}$ & $x$ & $x$ & $x$ & $x$ & Degree & - & - & $x$ & Internally & U \\
\hline Lotan (2009), , ${ }^{29} \mathrm{C}$ & $\mathrm{BCa}$ & $x$ & $x$ & $x$ & $x$ & Degree & - & - & $x$ & Externally & $U$ \\
\hline Lotan (2009),,$^{29} \mathrm{~d}$ & $\mathrm{BCa}$ & $x$ & $x$ & $x$ & $x$ & Degree & - & - & $x$ & Internally & U \\
\hline Barbieri (2012), ${ }^{17}$ a & $\mathrm{BCa}$ & $x$ & $x$ & $x$ & $x$ & Unspecified & - & - & - & None & $U$ \\
\hline Barbieri (2012), ${ }^{17}$ b & $\mathrm{BCa}$ & $x$ & $x$ & $x$ & $x$ & Unspecified & - & - & $x$ & None & U \\
\hline Barbieri (2012), ${ }^{17} \mathrm{C}$ & $\mathrm{BCa}$ & $x$ & $x$ & $x$ & $x$ & Unspecified & - & - & $x$ & None & U \\
\hline Barbieri (2012), ${ }^{17} d$ & $\mathrm{BCa}$ & $x$ & $x$ & $x$ & $x$ & Unspecified & - & - & $x$ & None & $U$ \\
\hline $\operatorname{Tan}(2019)^{33}$ & $\mathrm{BCa}$ & $x$ & $x$ & $x$ & - & Degree & - & - & - & Externally & $\mathrm{S}$ \\
\hline Georgieva (2019)10 & $\begin{array}{l}\mathrm{KCa}, \mathrm{BCa} \\
\mathrm{UCa}\end{array}$ & $x$ & $x$ & $x$ & - & History & - & - & - & Externally & S \\
\hline Matulewicz (2020)34 & $\mathrm{BCa}$ & $x$ & $x$ & $x$ & $x$ & $\mathrm{NVH}$ & - & - & - & - & $\mathrm{S}$ \\
\hline
\end{tabular}

Supplementary Table S5). Frequently the presence of haematuria, either any $(n=3)$, visible $(n=5)$, or non-visible $(n=2)$, was compared with no haematuria. One study reported the odds ratio (OR) separately for both VH IOR 26, 95\% confidence interval $[\mathrm{Cl}]=22$ to 30 ) and $\mathrm{NVH}$ (OR 20, $95 \% \mathrm{Cl}=12$ to 33 ) for bladder cancer. ${ }^{35}$ Four studies, developed in cohorts composed of individuals undergoing investigation for 


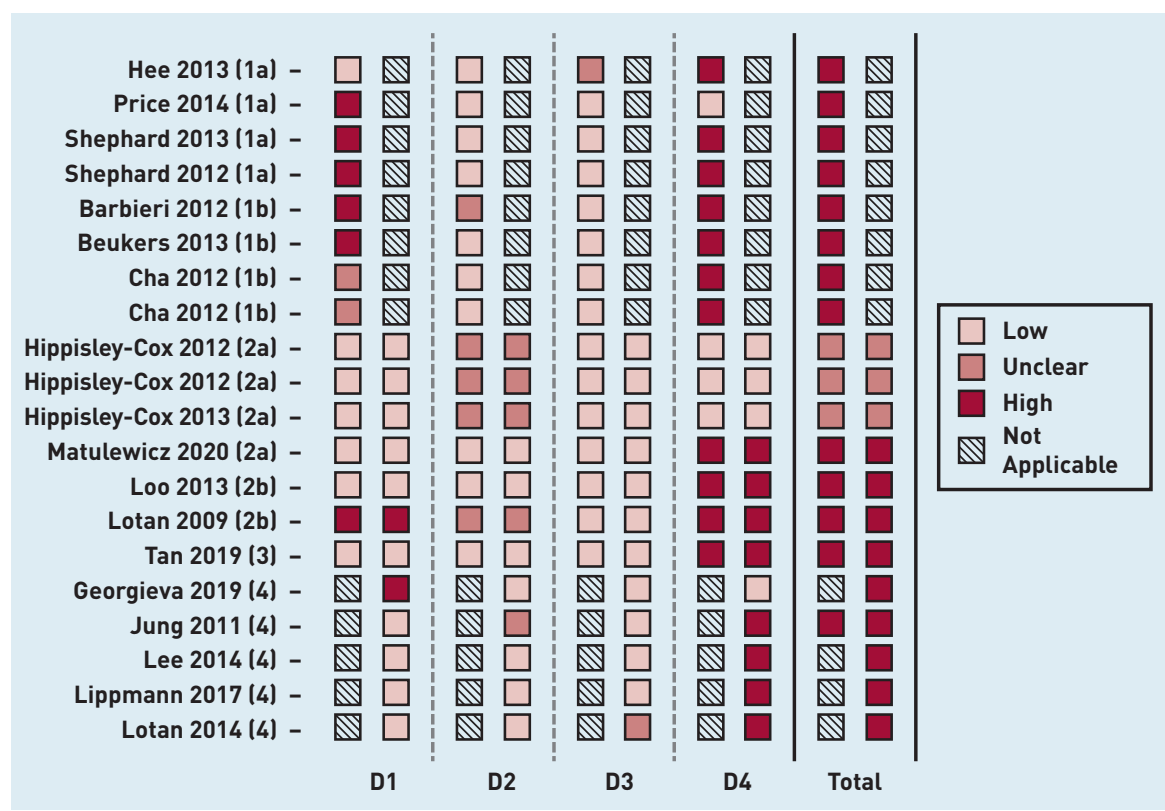

Figure 2. RoB assessment using PROBAST framework. ${ }^{a}$ a For each study, RoB is shown for model development and validation separately. RoB is assessed over four domains (D1: population, D2: risk factors, D3: outcome, D4: analysis), the overall results for each study are shown on the right. 1, 2, 3, and 4 refer to TRIPOD classification for each identified study. ${ }^{14} a, b$, and $c$ refer to models developed by the same author group. $R o B=$ risk of bias haematuria for suspected bladder cancer, gave ORs for individuals with $\mathrm{VH}$ compared with those with $\mathrm{NVH} .{ }^{18,20,21,33}$ All showed stronger associations with $\mathrm{VH}$ than $\mathrm{NVH}$ (OR 1.71-3.85 in multivariate analysis).

Seven models included other clinical features in addition to haematuria. ${ }^{22-24,31,32,35}$ These included abdominal pain $(n=7)$, weight loss ( $n=4)$, anaemia ( $n=3)$, loss of appetite $(n=3)$, urinary tract infection (UTI) $(n=3)$, and dysuria $(n=3)$. In each case, the risk because of haematuria was at least eight times higher than the risk from all other clinical features.

Demographic risk factors, including age $(n=27)$, sex ( $n=20)$, and ethnic group ( $n=9)$, were used in most models. Modifiable lifestyle risk factors, including smoking $(n=24)$ and BMI $(n=2)$, were also considered. Three models included abnormal blood tests; ${ }^{31,32}$ eight urine biomarkers ${ }^{17,18,20,29}$ and seven urine cytology. ${ }^{17,18,20,29}$

\section{RoB}

Most of the 20 studies included in this systematic review were assessed to have a high $\operatorname{RoB}(n=17)$ in both development and validation (Figure 2). The most common issues were seen in domain 4 (analysis), in which 11 of 15 development studies and eight of 12 validation studies were at high RoB. This was frequently because of an insufficient number of cases or incomplete reporting of performance measures (including not reporting calibration of model).

\section{Performance measures}

Discrimination (the AUROC) was reported for 26 models (Figure 3 and
Supplementary Table S6). Calibration was reported for 13 internal20,22-24,29,34 and three external validations. ${ }^{21,30,33}$

The four Hippisley-Cox and Coupland models, developed in unfiltered populationbased cohorts to predict urological cancer, all have AUROC values in the range $0.88-0.96$ in a large internal validation (Figure 3, group D). ${ }^{22-}$ ${ }^{24}$ These models report good calibration and relatively high levels of accuracy (sensitivity 0.77-0.71, specificity 0.90-0.91) when using the 90th percentile of risk as a cut-off. They also have high NPV (100\%) for PPVs in the range $0.6 \%-1.6 \%$ for this threshold. The two models developed for males have slightly higher discrimination than those for females. Demographic and lifestyle risk factors are combined with clinical features - smoking. haematuria, and abdominal pain feature in all four. Two specified $\mathrm{VH}$ as a symptom, whereas the other two did not specify type of haematuria. This did not significantly affect performance; however, other risk factors also differed between these models.

The models by Shephard et al and Price et al predicted the risk of developing kidney $^{31}$ and bladder ${ }^{32,35}$ cancer by combining pairs of symptoms observed in unfiltered population-based cohorts. The combinations of symptoms with the highest accuracy were microcytosis and abdominal pain for kidney cancer (PPV $>5 \%$ ), and $\mathrm{VH}$ and raised white blood cell count for bladder cancer (PPV 8.8\%). It is shown ${ }^{35}$ that, even in older age groups (>60 years), the PPV of $\mathrm{NVH}$ for bladder cancer is low $(0.8 \%)$, however, when combined with dysuria, for example, this increases to $4.5 \%$. These symptom combinations are rare $k<10$ cases out of 3140 in development population), so may have limited impact individually.

The model by Matulewicz et al ${ }^{34}$ was developed in a population with newly diagnosed $\mathrm{NVH}$ and had an AUROC value of $0.74(95 \% \mathrm{Cl}=0.67$ to 0.80$)$ in an internal validation (Figure 3, group A). This model combines a categorical measurement of NVH (red blood cells per high-power field [RBC/hpf]) with age, sex, smoking, and ethnic group to predict a likelihood of a bladder cancer diagnosis. For a threshold ( $>5 \%$ risk) that gives a PPV of $10.4 \%$, reasonable accuracy (sensitivity 68\%, specificity $75 \%$ ) and a high NPV (98\%) are demonstrated.

The remaining 20 models report discrimination in populations undergoing investigation for suspected urological cancer, with varying proportions of the populations having $\mathrm{VH}$ and $\mathrm{NVH}$ (Figure 3, groups $\mathrm{B}$ and $\mathrm{C}$ ). On average, discrimination is higher in models developed only in 


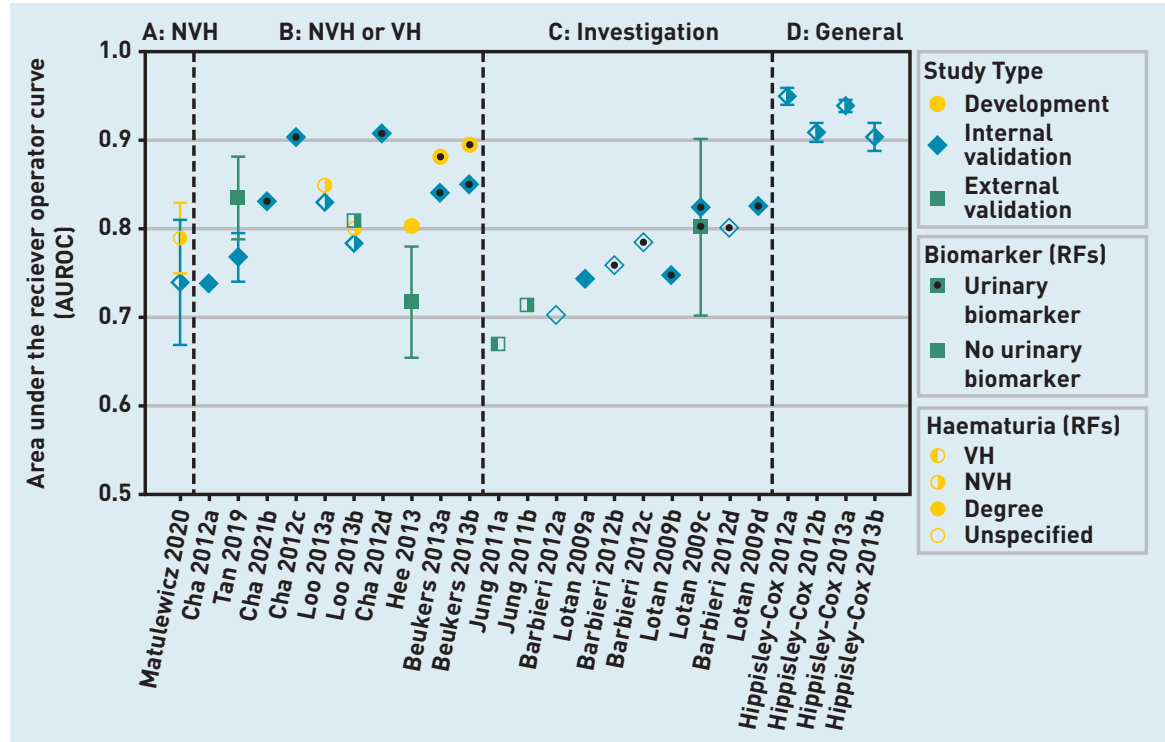

Figure 3. Model discrimination, AUROC. ${ }^{a}$

${ }^{a}$ Models are split into groups describing the development population and within each group are ordered by the number of risk factors used. Study type (development, internal and external validation), type of haematuria used in model, and study setting are indicated on the plot. $A, b$, and crefer to models developed by the same author group. Each model is labelled according to its development study; however, the discrimination measured in several external validations $s^{26,27,30}$ of these models are also included in this summary plot (see supplementary Table S6 for details). $A U R O C=$ area under the receiver operating curve. $\mathbf{N V H}=$ non-visible haematuria. $R F=$ risk factor. $\mathrm{VH}=$ visible haematuria.

\section{Funding}

Hannah Harrison was supported by a National Institute for Health Research (NIHR) Methods Fellowship (reference: RM-SR-2017-09-009) and is now supported by a NIHR Development and Skills Enhancement Award Ireference: NIHR301182). Juliet A Usher-Smith was funded by a Cancer Research UK Prevention Fellowship (reference: C55650/A21464). The University of Cambridge has received salary support in respect of Simon Griffin from the $\mathrm{NHS}$ in the East of England through the Clinical Academic Reserve. Sabrina H Rossi is funded by a Cancer Research UK Clinical PhD Fellowship. Grant D Stewart is funded by the Renal Cancer Research Fund, Kidney Cancer UK, Mark Foundation for Cancer Research, Cancer Research UK Cambridge Centre (reference: C9685/A25177), and NIHR Cambridge Biomedical Research Centre (reference: BRC-1215-20014). Fiona $\mathrm{M}$ Walter is co-director of the CanTest Collaborative, which is funded by Cancer Research UK (reference: CC8640/A23385). individuals with haematuria (group B) and in models that incorporate urinary biomarkers. The model with highest discrimination in external validation was Tan et al (2019) (AUROC = 0.77). ${ }^{33}$ This model combines type of haematuria with age, sex, and smoking status to predict the risk of a bladder cancer diagnosis. For an optimised cut-off point $(>4.015 \%)$ the reported accuracy measures indicate high sensitivity (0.99) can be achieved; however, the corresponding specificity was low (0.31). The best performing models incorporating urinary biomarkers are Cha et al (2012) model $c$ and Cha et al (2012) model d (AUROC $=0.9$ in internal validation). ${ }^{19}$ The degree of haematuria (VH or NVH) is combined with the uCyt assay lan immunocytochemical test that detects markers from malignant urothelial cells in urine $)^{36}$ and several demographic and lifestyle factors. Cha et al (2012) model d also included the results of cytology as a risk factor; this does not seem to improve model performance. The models by Loo et $a^{28}$ include an indication of the severity of $\mathrm{NVH}$ (>25 RBC/hpf); Loo et al (2013) model b has high discrimination (AUROC $=0.809$ ) in external validation. ${ }^{27}$

\section{DISCUSSION}

\section{Summary}

This review found 13 risk prediction models with good discrimination (>0.8) for urological cancer. All of the models included haematuria and seven incorporated additional clinical signs or symptoms. Most were developed in populations undergoing investigation for suspected urological cancer, with only seven developed in primary care lor unfiltered population-based) cohorts. Only eight of the identified models had been externally validated and around half $(n=14)$ had no reported measure of calibration.

\section{Strengths and limitations}

This is the first study, to the authors' knowledge, to provide a systematic and up-to-date review of the existing risk prediction models for bladder or kidney cancer with application to primary care. The study benefits from a comprehensive search and rigorous screening of studies for inclusion. In total, 29 models were identified in this process, providing a clear overview of the current research in this area. The PROBAST tool was used, a new quality assessment tool for risk prediction models, to perform a robust assessment of the RoB for each model and identify areas where the quality of research is low. It was not possible to perform a meta-analysis because of the heterogeneity in the study designs, including differences in study type (development and validation), design (cohort and case-control), setting (primary and secondary care), and recruitment criteria. A further limitation is that several models used coded information from primary care records and may be subject to bias in clinician recording and choice of investigations.

\section{Comparison with existing literature}

Recent reviews have examined risk assessment tools for the identification of other undiagnosed cancers, including colorecta ${ }^{37}$ and ovarian cancer. ${ }^{38}$ The models identified by those studies had similar discriminative ability to those described in this review. As in this review, a lack of high-quality studies and external validations was noted. There was a wider range of models developed specifically for primary care settings for those cancers, than have been identified in the current study for urological cancer.

Although $\mathrm{VH}$ has been widely shown to be associated with urological cancer, ${ }^{39}$ the association with other clinical factors (including NVH and UTIs) is poorly understood, ${ }^{7,39}$ with variation between different populations. ${ }^{40}$ In this review, only seven models included clinical factors other than haematuria and only five studies directly compared $\mathrm{VH}$ and $\mathrm{NVH}$ as risk factors. Additionally, haematuria has a much higher contribution than other clinical risk factors in all models where $>1$ is used.

\section{Implications for research and practice}

The seven models developed in primary care settings $s^{22-24,31,32,35}$ are the most applicable to this review question. The excellent 
Yin Zhou is funded by a Wellcome Trust Primary Care Clinician PhD Fellowship (reference: 20391/Z/16/Z). The funders had no role in the design and conduct of the study; collection, management, analysis, and interpretation of the data; and preparation, review, or approval of the manuscript. The views expressed in this publication are those of the authors and not necessarily those of the $\mathrm{NHS}$, the NIHR, or the Department of Health and Social Care.

\section{Ethical approval}

Not applicable.

\section{Data}

Templates of data extraction forms and code used to produce graphs are not publicly available, but will be provided on contacting the corresponding author.

\section{Provenance}

Freely submitted; externally peer reviewed.

\section{Competing interests}

Grant D Stewart has received educational grants from Pfizer, AstraZeneca, and Intuitive Surgical; consultancy fees from Pfizer, Merck, EUSA Pharma, and CMR Surgical; travel expenses from Pfizer; and speaker fees from Pfizer. All other authors have declared no competing interests.

\section{Acknowledgements}

The authors would like to thank Isla Kuhn for her help in developing the search strategy. The authors thank Zhirong Yang and Mila Petrova for their assistance in screening several nonEnglish full texts.

\section{Open access}

This article is Open Access: CC BY 4.0 licence (http://creativecommons.org/licences/ by/4.0/).

\section{Discuss this article}

Contribute and read comments about this article: bjgp.org/letters performance of the four Hippisley-Cox models, if replicated in an external validation, would make them suitable for use in primary care, in particular, they may enable clinicians to identify lowerrisk individuals who do not need referral. However, it is unclear how these models would be used and how this would compare with current practice. For example, it cannot be inferred if any individuals currently eligible for referral (such as those with $\mathrm{VH}$ ) would be reclassified using these models.

The model developed by Matulewizc, ${ }^{34}$ in a population with newly identified $\mathrm{NVH}$, could be used in primary care to guide referral decisions in individuals with $\mathrm{NVH}$. Current guidelines for referral for suspected urological cancer in the UK differentiate between types of haematuria ( $\mathrm{VH}$ and $\mathrm{NVH}$ ) and age ( $>45$ and $>60$ years, respectively). There is concern that lower-risk patients, such as younger individuals with $\mathrm{NVH}$, are not managed optimally. ${ }^{7}$ The Matulewizc model, by combining a categorical measure of NVH with demographic factors, identifies both high- and low-risk individuals successfully (PPV 10.4\% and NPV 98.2\%). This suggests that this model could identify some individuals with $\mathrm{NVH}$ who are aged $<60$ years who would benefit from referral and some aged $>60$ years who are at lower risk and do not need referral. The high PPVs seen when using this model, and when NVH was combined with other clinical signs in the study by Price et $a l_{1}^{35}$ indicate the need to consider the broader clinical context when making referral decisions in patients with $\mathrm{NVH}$.

In conclusion, haematuria was the strongest clinical risk factor associated with urological cancers and was included in all of the models identified. Several models have been developed in primary care populations that could be used to guide referrals, in particular, identifying those at lower risk least likely to benefit from further investigation. Additionally, one model was identified that could be used to stratify the risk of cancer in individuals presenting with $\mathrm{NVH}$.

Future research in this area should initially focus on carrying out external validations of the identified models in a suitable primary care cohort. Researchers should then consider the impact that implementing these models to support referral decisions would have on both patient outcomes and the healthcare service in their analyses. 


\section{REFERENCES}

1. Cancer Research UK. Bladder cancer statistics. https://www.cancerresearchuk. org/health-professional/cancer-statistics/statistics-by-cancer-type/bladdercancer laccessed 17 Nov 2021).

2. Cancer Research UK. Kidney cancer statistics. https://unw.cancerresearchuk org/health-professional/cancer-statistics/statistics-by-cancer-type/kidneycancer laccessed 17 Nov 2021).

3. National Cancer Intelligence Network. Routes to diagnosis 2006-2015 workbook. 2017. http://www.ncin.org.uk/publications/routes_to_diagnosis laccessed 17 Nov 2021).

4. Neal RD, Tharmanathan P, France B, et al. Is increased time to diagnosis and treatment in symptomatic cancer associated with poorer outcomes? Systematic review. Br J Cancer 2015; 112 (Suppl 1): S92-S107.

5. Arhi CS, Burns EM, Bottle A, et al. Delays in referral from primary care worsen survival for patients with colorectal cancer: a retrospective cohort study. $\mathrm{Br} \mathrm{J}$ Gen Pract 2020; DOI: https://doi.org/10.3399/bjgp20X710441.

6. Zhou Y, Walter FM, Singh $\mathrm{H}$, et al. Prolonged diagnostic intervals as marker of missed diagnostic opportunities in bladder and kidney cancer patients with alarm features: a longitudinal linked data study. Cancers (Basel) 2021; 13(1): 156.

7. Zhou Y, Funston G, Lyratzopoulos G. Walter FM. Improving the timely detection of bladder and kidney cancer in primary care. Adv Ther 2019; 36(7): 1778-1785.

8. National Institute for Health and Care Excellence. Suspected cancer: recognition and referral. NG12. 2021. http://www.nice.org.uk/guidance/NG12 (accessed 17 Nov 2021).

9. Zhou Y, Mendonca SC, Abel GA, et al. Variation in 'fast-track' referrals for suspected cancer by patient characteristic and cancer diagnosis: evidence from 670000 patients with cancers of 35 different sites. Br J Cancer 2018; 118(1): 24-31.

10. Georgieva MV, Wheeler SB, Erim D, et al. Comparison of the harms, advantages, and costs associated with alternative guidelines for the evaluation of hematuria. JAMA Intern Med 2019; 179(10): 1352-1362.

11. Hamilton W, Green T, Martins T, et al. Evaluation of risk assessment tools for suspected cancer in general practice: a cohort study. Br J Gen Pract 2013, 63(606): e30-e36.

12. Grigore B, Lewis R. Peters J, et al. Development, validation and effectiveness of diagnostic prediction tools for colorectal cancer in primary care: a systematic review. BMC Cancer 2020; 20(1): 1084

13. Hamilton W, Green T, Martins T, et al. Evaluation of risk assessment tools for suspected cancer in general practice: a cohort study. Br J Gen Pract 2013; DOI: https://doi.org/10.3399/bjgp13X660751

14. Moons KG, Altman DG, Reitsma JB, et al. Transparent Reporting of a multivariable prediction model for Individual Prognosis or Diagnosis (TRIPOD): explanation and elaboration. Ann Intern Med 2015; 162(1): W1-W73.

15. Moons KGM, Wolff RF, Riley RD, et al. PROBAST: a tool to assess risk of bias and applicability of prediction model studies: explanation and elaboration. Ann Intern Med 2019; 170(1): W1-W33.

16. Wolff RF, Moons KGM, Riley RD, et al. PROBAST: a tool to assess the risk of bias and applicability of prediction model studies. Ann Intern Med 2019; 170(1): $51-58$

17. Barbieri CE, Cha EK, Chromecki TF, et al. Decision curve analysis assessing the clinical benefit of NMP22 in the detection of bladder cancer: secondary analysis of a prospective trial. BJU Int 2012; 109(5): 685-690.

18. Beukers W, Kandimalla R, van Houwelingen D, et al. The use of molecular analyses in voided urine for the assessment of patients with hematuria. PLOS One 2013; 8(10): e77657.

19. Cha EK, Tirsar LA, Schwentner C, et al. Immunocytology is a strong predictor of bladder cancer presence in patients with painless hematuria: a multicentre study. Eur Urol 2012; 61(1): 185-192.
20. Cha EK, Tirsar LA, Schwentner C, et al. Accurate risk assessment of patients with asymptomatic hematuria for the presence of bladder cancer. World J Urol 2012; 30(6): 847-852

21. Hee TG, Shah SA, Ann HS, et al. Stratifying patients with haematuria into high or low risk groups for bladder cancer: a novel clinical scoring system. Asian Pac J Cancer Prev 2013; 14(11): 6327-6330.

22. Hippisley-Cox J, Coupland C. Identifying patients with suspected renal tract cancer in primary care: derivation and validation of an algorithm. $\mathrm{Br} J \mathrm{Gen}$ Pract 2012; DOI: https://doi.org/10.3399/bjgp12X636074.

23. Hippisley-Cox J, Coupland C. Symptoms and risk factors to identify men with suspected cancer in primary care: derivation and validation of an algorithm. $\mathrm{Br}$ J Gen Pract 2013; DOI: https://doi.org/10.3399/bjgp13X660724.

24. Hippisley-Cox J, Coupland C. Symptoms and risk factors to identify women with suspected cancer in primary care: derivation and validation of an algorithm. $\mathrm{Br}$ J Gen Pract 2013; DOI: https://doi.org/10.3399/bjgp13X660733.

25. Jung $\mathrm{H}$, Gleason J, Loo R, et al. Association of hematuria on microscopic urinalysis and risk of urinary tract cancer development. Eur Urol Supp 2010; DOI: 10.1016/j.juro.2010.02.414.

26. Lee SB, Kim HS, Kim M, Ku JH. External validation of a clinical scoring system for hematuria. Asian Pac J Cancer Prev 2014; 15(16): 6819-6822

27. Lippmann QK, Slezak JM, Menefee SA, et al. Evaluation of microscopic hematuria and risk of urologic cancer in female patients. Am J Obstet Gynecol 2017; 216(2): 146.e1-146.e7.

28. Loo RK, Lieberman SF, Slezak JM, et al. Stratifying risk of urinary tract malignant tumors in patients with asymptomatic microscopic hematuria. Mayo Clin Proc 2013; 88(2): 129-138.

29. Lotan Y, Capitanio U, Shariat SF, et al. Impact of clinical factors, including a point-of-care nuclear matrix protein-22 assay and cytology, on bladder cancer detection. BJU Int 2009; 103(10): 1368-1374.

30. Lotan Y, Svatek RS, Krabbe LM, et al. Prospective external validation of a bladder cancer detection model. J Urol 2014; 192(5): 1343-1348.

31. Shephard E, Neal R, Rose $P$, et al. Clinical features of kidney cancer in primary care: a case-control study using primary care records. Br J Gen Pract 2013; DOI: https://doi.org/10.3399/bjgp13X665215.

32. Shephard EA, Stapley S, Neal RD, et al. Clinical features of bladder cancer in primary care. Br J Gen Pract 2012; DOI: https://doi.org/10.3399/bjgp12X654560.

33. Tan WS, Ahmad A, Feber A, et al. Development and validation of a haematuria cancer risk score to identify patients at risk of harbouring cancer. J Intern Med 2019; 285(4): 436-445

34. Matulewicz RS, Rademaker A, Meeks JJ. A simplified nomogram to assess risk of bladder cancer in patients with a new diagnosis of microscopic hematuria. Urol Oncol 2020; 38(4): 240-246.

35. Price SJ, Shephard EA, Stapley SA, et al. Non-visible versus visible haematuria and bladder cancer risk: a study of electronic records in primary care. $\mathrm{Br} J \mathrm{Gen}$ Pract 2014; DOI: https://doi.org/10.3399/bjgp14X681409.

36. Greene KL, Berry A, Konety BR. Diagnostic utility of the immunoCyt/uCyt+ test in bladder cancer. Rev Urol 2006; 8(4): 190-197.

37. Williams TGS, Cubiella J, Griffin SJ, et al. Risk prediction models for colorectal cancer in people with symptoms: a systematic review. BMC Gastroenterol 2016; 16(1): $63-63$

38. Funston $G$, Hardy V, Abel G, et al. Identifying ovarian cancer in symptomatic women: a systematic review of clinical tools. Cancers (Basel) 2020; 12(12): 3686

39. Schmidt-Hansen M, Berendse S, Hamilton W. The association between symptoms and bladder or renal tract cancer in primary care: a systematic review. Br J Gen Pract 2015; DOI: https://doi.org/10.3399/bjgp15X687421.

40. Kelly JD, Fawcett DP, Goldberg LC. Assessment and management of nonvisible haematuria in primary care. BMJ 2009; 338: a3021. 